Article

\title{
Facile Synthesis of Di-Mannitol Adipate Ester-Based Zinc Metal Alkoxide as a Bi-Functional Additive for Poly(Vinyl Chloride)
}

\author{
Yuepeng $\mathrm{Li}^{1}$, Degang $\mathrm{Li}^{1, *}{ }^{1}$, Wenyuan Han ${ }^{1}$, Manqi Zhang ${ }^{1}$, Bing Ai ${ }^{1}$, Lipeng Zhang ${ }^{1, *}$, \\ Hongqi Sun ${ }^{2}$ and Zhen $\mathrm{Cui}^{3}$ \\ 1 School of Chemistry and Chemical Engineering, Shandong University of Technology, Zibo 255000, China; \\ 13864306952@163.com (Y.L.); 18753375118@163.com (W.H.); 17853321663@163.com (M.Z.); \\ hgxyaibing@163.com (B.A.) \\ 2 School of Engineering, Edith Cowan University, 270 Joondalup Drive, Joondalup, WA 6027, Australia; \\ h.sun@ecu.edu.au \\ 3 Weifang Zhengxuan Rare Earth Catalytic Materials Co., Ltd., Weifang 262737, China; zzciuzhen@sina.com \\ * Correspondence: ldg@sdut.edu.cn (D.L.); zhanglipeng@sdut.edu.cn (L.Z.)
}

Received: 30 March 2019; Accepted: 30 April 2019; Published: 6 May 2019

\begin{abstract}
A new di-mannitol adipate ester-based zinc metal alkoxide (DMAE-Zn) was synthesized as a bi-functional poly(vinyl chloride) (PVC) thermal stabilizer for the first time. The materials were characterized with Fourier transform infrared spectroscopy (FT-IR) and thermogravimetric analysis (TGA). Characterization results confirmed the formation of $\mathrm{Zn}-\mathrm{O}$ bonds in DMAE-Zn, and confirmed that DMAE-Zn had a high decomposition temperature and a low melting point. The thermal stability of DMAE-Zn on PVC also was tested by a conductivity test, a thermal aging test, and a UV-visible spectroscopy (UV-VIS) test. PVC stabilized by DMAE-Zn had a good initial color and excellent long-term stability. UV-VIS also showed that the conjugated structure in PVC stabilized by DMAE-Zn was almost all of the triene, suggesting that the addition of DMAE-Zn would suppress the formation of conjugated structures above tetraene. The dynamic processing performance of PVC samples tested by torque rheometer indicated that, having a good compatibility with PVC chains in the amorphous regions, DMAE-Zn contributed a good plasticizing effect to PVC. DMAE-Zn thus effectively demonstrates bi-functional roles, e.g., thermal stabilizers and plasticizers to PVC. Furthermore, FT-IR, a $\mathrm{HCl}$ absorption capacity test, and a complex $\mathrm{ZnCl}_{2}$ test were also used to verify the thermal stability mechanism of DMAE-Zn for PVC.
\end{abstract}

Keywords: PVC; thermal stabilizers; bi-functional; di-mannitol adipate ester-based zinc metal alkoxide; plasticizers

\section{Introduction}

Poly(vinyl chloride) (PVC) is one of the five general plastics, and has been widely used in infrastructure construction and home supplies because of its excellent low cost, high strength, corrosion resistance, and self-extinguishing capability, etc. [1]. In applications, its poor thermal stability is the biggest weakness of PVC. When the temperature reaches $130{ }^{\circ} \mathrm{C}$ or higher, PVC starts to break down and release hydrogen chloride $(\mathrm{HCl})$, which can further aggravate this degradation process [2]. The color of PVC changes significantly from white to brown, and finally black, while its mechanical properties also decline rapidly [3]. Therefore, thermal stabilizers must be added during PVC processing to inhibit the production of $\mathrm{HCl}$ and remove the free $\mathrm{HCl}$ [4].

At present, lead salts, metal soap, and organotin are the mainstream thermal stabilizers used in PVC. Although lead salts provide the best thermal stability of PVC, their toxicity restricts their 
application. Metal soap, such as calcium stearate $\left(\mathrm{CaSt}_{2}\right)$ and zinc stearate $\left(\mathrm{ZnSt}_{2}\right)$, has no toxicity, but its thermal stabilizing effect on PVC is not ideal, especially as "zinc-burning" leads to the rapid degradation of PVC [5-10]. Organotin provides an excellent thermal stability of PVC, but its cost is too high [11]. It is then necessary to develop new non-toxic and efficient thermal stabilizers of PVC [12-14].

A number of new types of thermal stabilizers, for example, zinc and calcium salts of 11-maleimideoundecanoic acid, synthesized liquid $\mathrm{Ca} / \mathrm{Zn}$ thermal stabilizer, zinc and calcium oxolinic complexes, ricinoleic acid-based $\mathrm{Ca} / \mathrm{Zn}$ stabilizer have been reported [11,13,15-19]. Some researchers also indicated that polyols can serve as auxiliary thermal stabilizers. As they have many hydroxyl groups, polyols are able to chelate $\mathrm{ZnCl}_{2}$ to inhibit the "zinc-burning" phenomenon [3,20]. Jenneskens et al. found that natural polyols can significantly improve the thermal stability of PVC [21,22]. Guo et al. reported that the addition of pentaerythritol combined with $\mathrm{CaSt}_{2} / \mathrm{ZnSt}_{2}$ could improve the thermal and color stability of PVC [23].

Recently, we synthesized a series of polyol-based metal alkoxides as PVC thermal stabilizers, and showed that they were efficient in inhibiting the degradation of PVC [24,25]. There is still a challenge for these polyol-based metal alkoxides to be used as PVC thermal stabilizers, because their melting point (about $220^{\circ} \mathrm{C}$ ) [1,2] is significantly higher than the processing temperature of PVC, affecting their consistency with PVC [26]. In order to reduce the melting point of polyol-based metal alkoxides, Shentu et al. employed mannitol with a low melting point of $166^{\circ} \mathrm{C}$ to synthesize mannitol-zinc metal alkoxides, which was then used to improve PVC thermal stability [2]. A new strategy was applied by our group to overcome this shortcoming by esterification. For example, we synthesized pentaerythritol stearate ester-based zinc alkoxides (PSE-Zn) [26] and cis-1,2-cyclohexanedicarboxylic acid di-mannitol ester-based zinc metal alkoxides [27]. We observed that the new ester-based alkoxides have a lower melting point and a good thermal stabilization performance on PVC.

Generally speaking, a plasticizer, one of the most important PVC processing aids, should be added to adjust the mechanical and thermal properties of PVC. Phthalate esters are the most commonly used plasticizers in PVC processing. However, most phthalate plasticizers are known to be toxic [28]. More and more researchers are committed to developing new non-toxic PVC plasticizers. It is recommended to use sustainable alternatives instead of phthalate esters. Epoxidized vegetable oils are one of these alternatives [28,29].

In this study, in order to lower the melting point of metal alkoxides, adipic acid was used to synthesize a new kind of thermal stabilizer, di-mannitol adipate ester-based zinc metal alkoxide (DMAE-Zn). Adipic acid was chosen because it has good compatibility with PVC, enabling the plasticizing effect of DMAE-Zn on PVC. The synthesized DMAE-Zn was characterized by FT-IR spectroscopy and thermogravimetric analysis. Their thermal stability performances of PVC also were tested through the oven aging method, a conductivity test, a UV-VIS spectroscopy test, and a torque rheometer test. It was found that DMAE-Zn can effectively have a bi-functional role in PVC, acting as both a thermal stabilizer and a plasticizer.

\section{Experimental}

\subsection{Materials}

PVC resin (type SG-5, average degree of polymerization: 1005, viscosity number: 67) was from Petrochemical Qilu Limited Co., Zibo, China. Some additives, such as lead salt stabilizers (the mixture of tribasic lead sulfate, dibasic lead phosphite, polyethylene wax, and assistant agents, $\mathrm{PbO}$ content: $30 \pm 2 \%$ ), $\mathrm{CaSt}_{2}(98 \%), \mathrm{ZnSt}_{2}(98 \%)$, dioctyl phthalate (DOP, 99\%), $\mathrm{TiO}_{2}$ (anatase titanium dioxide, $99 \%$ ), chlorinated polyethylene (CPE, chlorine content: $35 \pm 2 \%$ ), acrylics copolymer (ACR, 99\%), and $\mathrm{CaCO}_{3}$ (light calcium carbonate, 1800 mesh), were all of industrial grade and were kindly supplied by Shandong Huike Additives Co., Zibo, China. D-mannitol ( $\geq 99.0 \%)$, adipic acid $(\geq 98 \%)$, cyclohexane $(\geq 99.0 \%)$, zinc acetate $(98 \%)$, and other chemical agents were all of analytical grade and were supplied by Shanghai McLean Biochemical Technology Co., LTD, Shanghai, China. 


\subsection{Preparation Process}

\subsubsection{Preparation of Di-Maltitol Adipate Ester}

Di-mannitol adipate ester (DMAE) was prepared by a traditional method. D-mannitol and adipic acid in a molar ratio of 2:1 were added into a mixer set and stirred for $5 \mathrm{~min}$. Then, the mixture was put into a $500 \mathrm{~mL}$ three-necked round bottom flask with mechanical stirring and a reflux water device, followed by the introduction of cyclohexane as the dehydrant. The mixture was heated to $160 \pm 1{ }^{\circ} \mathrm{C}$ for $3 \mathrm{~h}$, to remove the excess cyclohexane with a vacuum pump. The DMAE was then obtained.

\subsubsection{Preparation of Di-Mannitol Adipate Ester-Based Zinc Metal Alkoxide (DMAE-Zn)}

DMAE-Zn was synthesized through the method of alcoholysis. Zinc acetate and DMAE in a molar ratio of 1:1 were mixed in a three-necked flask with a mechanical stirring. Excess absolute ethanol was added and the reactor was then heated to $160 \pm 1{ }^{\circ} \mathrm{C}$ for $4 \mathrm{~h}$. After the solvent was evaporated, the samples were washed with ethanol three times to obtain the product of DMAE-Zn.

\subsection{Material Characterization}

Samples were characterized by Fourier transform infrared (FT-IR) spectroscopy (Nicolet 5700, Beijing, China) with the $\mathrm{KBr}$ disc method. The spectral range was $400-4000 \mathrm{~cm}^{-1}$, with a scan rate $128 \mathrm{~min}^{-1}$ and a resolution of $4 \mathrm{~cm}^{-1}$. The blank spectrum was tested before each measurement to eliminate the spectrum subtraction resulting from carbon dioxide and water in the air. Thermogravimetric analysis (TGA) and derivative thermogravimetry (DTG) of the samples were performed using a Q500 analyzer (TA instruments, Selb, Germany) at a $10^{\circ} \mathrm{C} \mathrm{min}^{-1}$ heating rate from 25 to $700{ }^{\circ} \mathrm{C}$ in a nitrogen atmosphere. The results were used to investigate the decomposition of the materials [26].

\subsection{PVC Sample Preparation}

About $100.0 \mathrm{~g}$ of PVC, $5 \mathrm{~mL}$ of dioctyl phthalate (DOP), $4.0 \mathrm{~g}$ of $\mathrm{TiO}_{2}, 9.0 \mathrm{~g}$ of chlorinated polyethylene (CPE), $2.0 \mathrm{~g}$ of acrylics copolymer (ACR), $20.0 \mathrm{~g}$ of $\mathrm{CaCO}_{3}, 1.6 \mathrm{~g}$ of stearic acid, and $4 \mathrm{~g}$ of thermal stabilizers were added into a blender to undergo sufficient mixing. Then the mixture was milled using an open twin-roller (PX-GY-150, Shenzhen Pengxiang Yunda Machinery Technology Co., Shenzhen, China) at $180^{\circ} \mathrm{C}$ for $5 \mathrm{~min}$ to produce the PVC sheets with a thickness of about $1.0 \mathrm{~mm}$.

\subsection{Thermal Stability Test}

\subsubsection{Conductivity Measurement}

PVC sheets were cut into small square pieces of $0.5 \mathrm{~mm} \times 0.5 \mathrm{~mm}$ with a total weight of $2.0 \mathrm{~g}$, and put into a home-made reaction vessel. The vessel was placed in an oil bath and heated to $180^{\circ} \mathrm{C}$. Then $60 \mathrm{~mL}$ of deionized water was added in a beaker of $100 \mathrm{~mL}$ to test its conductivity. The $\mathrm{HCl}$ gas produced during the thermal decomposition of PVC was introduced into the measuring beaker by the nitrogen stream (about $7 \mathrm{~L} / \mathrm{h}$ ). The $\mathrm{HCl}$ was absorbed by the deionized water in the measuring beaker so that the conductivity of water gradually changed with time. Therefore, the decomposition rate of PVC could be recorded through measuring the change of the conductivity of the deionized water. A conductivity meter (DDS-307, Shanghai Instrument Electric Scientific Instrument Co., Ltd., Shanghai, China) was used to measure the conductivity.

\subsubsection{Thermal Aging Test}

PVC sheets were cut into small samples of $15 \mathrm{~mm} \times 15 \mathrm{~mm}$. These sheets were heated to $180{ }^{\circ} \mathrm{C}$ in an oven. The sheets were taken out after every $10 \mathrm{~min}$. The thermal stability of PVC was evaluated by monitoring the color change. 


\subsubsection{UV-VIS Spectroscopy Test}

It is known that PVC begins to decompose and produce conjugated double bonds when the temperature reaches $130{ }^{\circ} \mathrm{C}$. PVC samples were first dissolved by tetrahydrofuran (THF). Then the concentration of conjugated double bonds was measured by UV-visible spectrometer (UV-VIS). The UV-VIS spectra were recorded at $25 \pm 5^{\circ} \mathrm{C}$ using a UV-2450PC spectrometer with the slit width set at $2 \mathrm{~nm}$ over the wavelength range of $200-500 \mathrm{~nm}$.

\subsubsection{Torque Rheometer Test}

The effect of DMAE-Zn on the dynamic rheological properties of PVC was tested by a torque rheometer (RM-200C, Harbin Harp Electric Technology Co., Harbin, China). The operating temperature was set at $180^{\circ} \mathrm{C}$ while keeping the rotor at a speed of $35 \mathrm{rpm}$.

\subsubsection{Capacity for Neutralizing $\mathrm{HCl}$}

The capacity of stabilizers to neutralize $\mathrm{HCl}$ was investigated by conductometric titration experiments. First, $6.00 \mathrm{~mL}$ of $0.1 \mathrm{M} \mathrm{HCl}$ standard solution was diluted with $20.00 \mathrm{~mL}$ of ethanol and $10.00 \mathrm{~mL}$ of deionized water. Then, $0.0500 \mathrm{~g}$ of thermal stabilizer, such as DMAE-Zn, lead salts, $\mathrm{ZnSt}_{2}, \mathrm{CaSt}_{2}$, and so on was dissolved in this solution with a magnetic stirring at $40{ }^{\circ} \mathrm{C}$. The excess $\mathrm{HCl}$ was back-titrated with $6.00 \mathrm{~mL}$ of $0.1 \mathrm{M} \mathrm{NaOH}$ standard solution. The conductivity of the solution was measured by a conductivity meter (DDS-307, same as in Section 2.5.1). The volume of $\mathrm{NaOH}$ solution corresponding to the minimum conductivity of the solution was the titration endpoint, and the capacity for neutralizing $\mathrm{HCl}$ was calculated by the volume of $\mathrm{NaOH}$ solution used.

\section{Results and Discussion}

\subsection{Characterization of Metal Alkoxides}

\subsubsection{Fourier Transform Infrared Spectroscopy}

Figure 1 is the FT-IR spectra of the synthesized DMAE and DMAE-Zn. Figure 1 shows that both the DMAE and DMAE-Zn have strong peaks at $3400-3500 \mathrm{~cm}^{-1}$, which represent the characteristic absorbance band of $-\mathrm{OH}$, as a result of the stretching vibration. The peak at about $2900 \mathrm{~cm}^{-1}$ corresponds to the stretching vibration of the $-\mathrm{C}-\mathrm{H}$ groups. The absorption peak at about $1738 \mathrm{~cm}^{-1}$ can be assigned to the ester carbonyl bonds $(-\mathrm{C}=\mathrm{O})$. There were no absorption peaks at $1786 \mathrm{~cm}^{-1}$ of carboxylic acid carbonyl bonds in DMAE and DMAE-Zn, indicating that the esterification of stearic acid with D-mannitol was complete. The absorption bands between 650 and $550 \mathrm{~cm}^{-1}$ in Figure $1 \mathrm{~b}$ are attributed to the $-\mathrm{O}-\mathrm{Zn}$ bonds [24]. The appearance of $-\mathrm{O}-\mathrm{Zn}$ bands indicated that the synthesized compound contained metal alkoxides.

There are six hydroxyl groups in a D-mannitol molecule. All of these hydroxyl groups can be esterified using adipic acid. Therefore, DMAE may contain more than 12 esters. Its derivative, DMAE-Zn, is expected to have a more complex structure. Scheme 1 shows a simplified reaction pathway for the synthesis of DMAE-Zn. Two carboxyl groups of adipic acid react with two alcoholic hydroxy groups of the di-mannitol to form esters. Then, through an alcoholysis reaction, the ethyoxyl of ethanol zinc will exchange with the hydroxy of polyol ester. After completely evaporating the ethanol, the targeted DMAE-Zn can be obtained. 


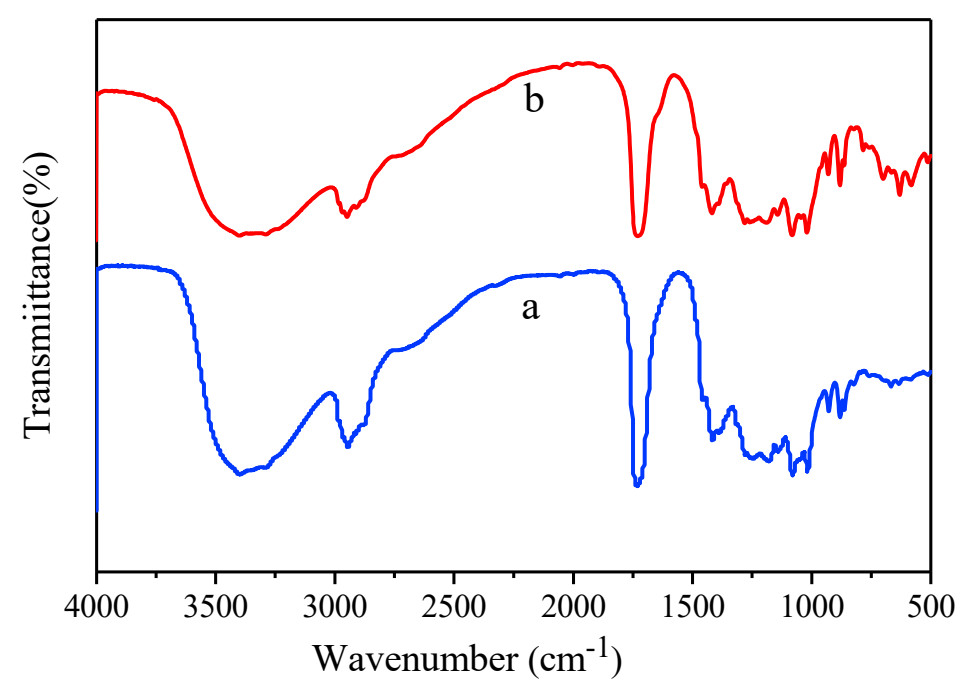

Figure 1. FT-IR spectra of the raw material and product: (a) di-mannitol adipate ester (DMAE); (b) di-mannitol adipate ester-based zinc metal alkoxide (DMAE-Zn).

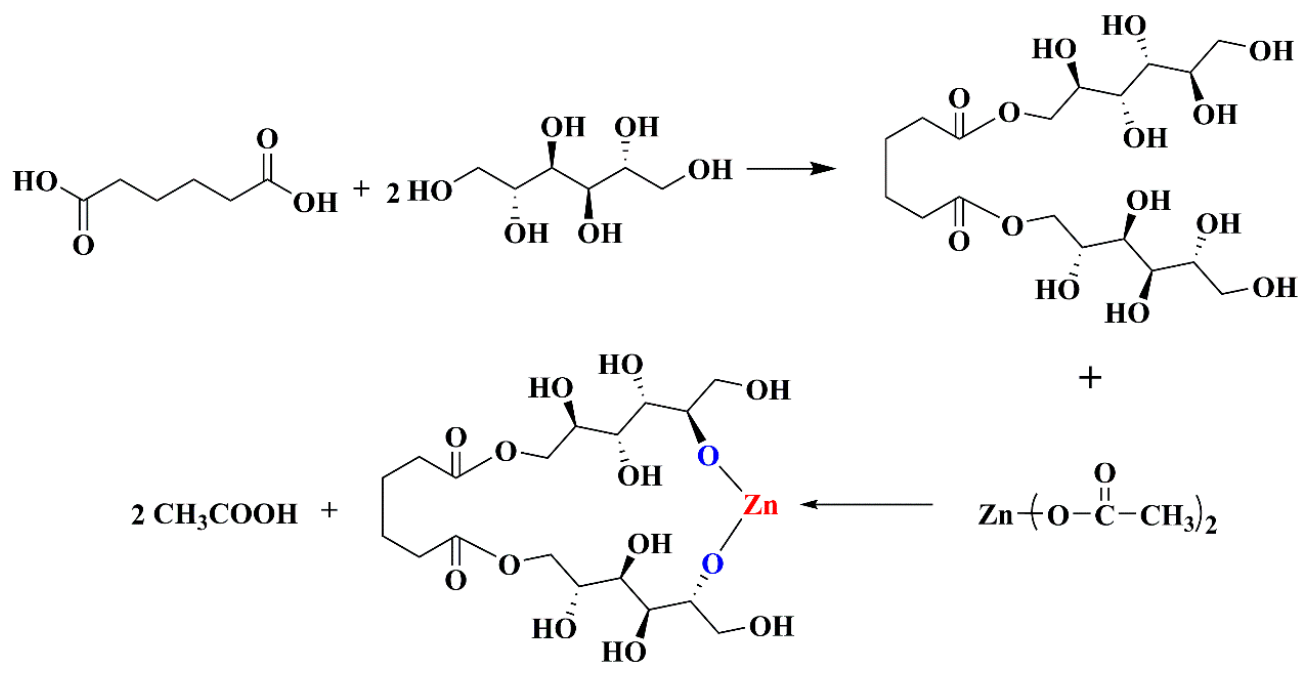

Scheme 1. Synthesis pathways of DMAE-Zn.

\subsubsection{Thermogravimetric Analysis}

Figure 2 shows the TGA, differential thermal analysis (DTA), and DTG curves of the targeted DMAE-Zn. There was one weight-loss step within the temperature range from 200 to $500{ }^{\circ} \mathrm{C}$ in the TG curve of the DMAE-Zn, which was accompanied by a maximum weight-loss peak. The DTG curve of Figure 2 shows that there are two pyrolysis temperatures for DMAE-Zn-265.8 and $342.5^{\circ} \mathrm{C}$. All the pyrolytic temperatures were far more than $180^{\circ} \mathrm{C}$, which is the processing temperature of PVC, meaning that the synthesized DMAE-Zn did not break down during PVC processing and was suitable for use as a thermal stabilizer of PVC. The TG curve in Figure 2 shows that the residue was 20.57\%, which is slightly higher than the result of the elemental analysis. The residue might be composed of $\mathrm{ZnO}$ and carbon. The DTA curve in Figure 2 shows that the melting point of the targeted DMAE- $\mathrm{Zn}$ can be estimated from the first endothermic peak where the weight changes slightly. Thus, the melting point of DMAE-Zn can be estimated to be $154.4{ }^{\circ} \mathrm{C}$, lower than the PVC processing temperature $\left(180^{\circ} \mathrm{C}\right)$. Therefore, the targeted metal alkoxides had good compatibility with PVC. 


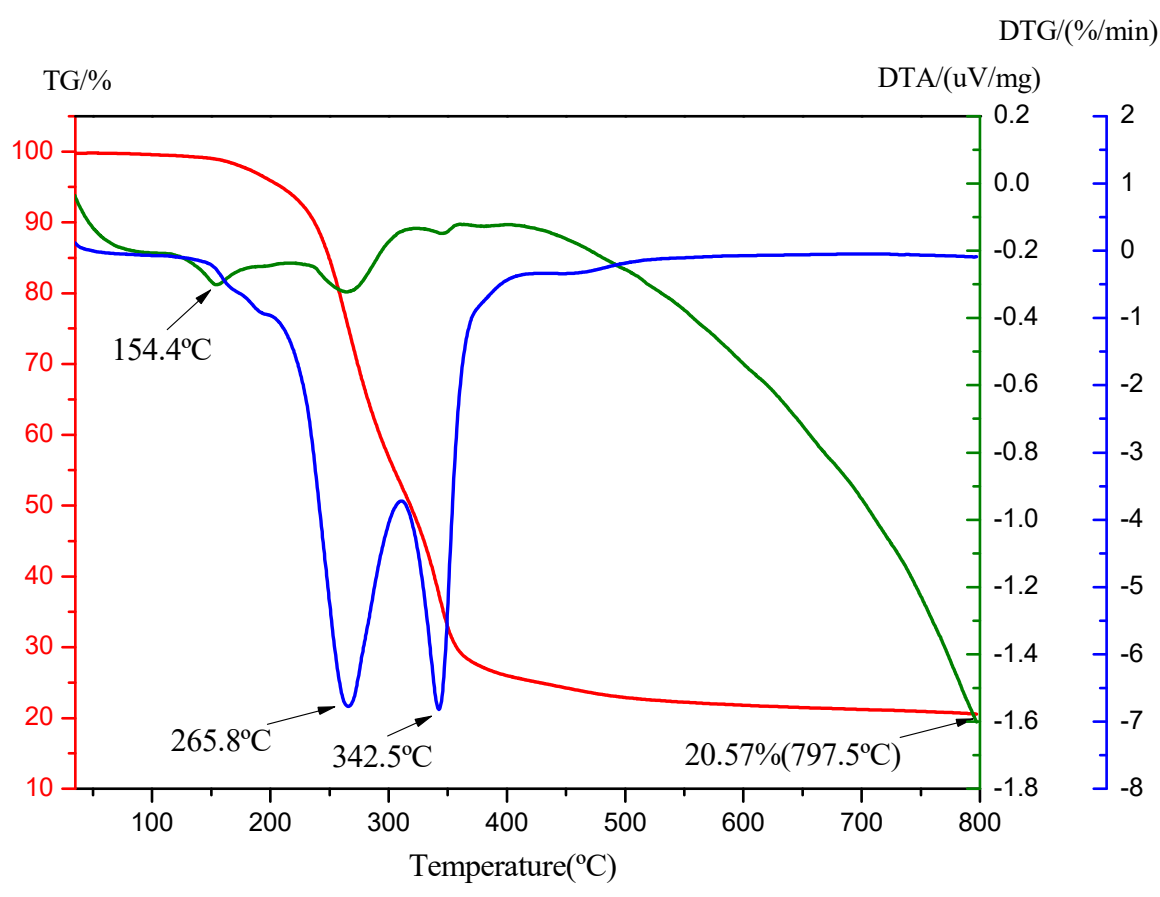

Figure 2. Thermogravimetric analysis (TGA), differential thermal analysis (DTA), and derivative thermogravimetry (DTG) curves of the targeted DMAE-Zn.

\subsection{Thermal Stability Tests of DMAE-Zn on PVC}

\subsubsection{Conductivity Test}

In the tests, nitrogen gas, as a carrier gas, carries $\mathrm{HCl}$ gas released during the degradation of PVC into deionized water. The dissolution of $\mathrm{HCl}$ into the deionized water changes the conductivity of the water. As a result, the degradation rate of PVC can be estimated by testing the rate of change in the conductivity of the water. In the conductivity vs. time plot, the introduction time $\left(T_{\mathrm{i}}\right)$ refers to the time from the start of the heating to when the conductivity starts to rise, while the stability time $\left(T_{\mathrm{s}}\right)$ refers to the time where the conductivity of the water reaches $50 \mu \mathrm{S} \mathrm{cm}^{-1}$ [30], which can be considered as the maximum acceptable conductivity value in PVC degradation.

Figure 3 shows the conductivity vs. time plots for pure PVC and PVC stabilized by $4 \mathrm{phr}$ (parts by weight per hundred parts of resin) of $\mathrm{ZnSt}_{2} / \mathrm{CaSt}_{2}$ (1:1), and DMAE-Zn. Generally speaking, the shorter the $T_{\mathrm{i}}$, the worse the color stability of PVC. It can be seen from Figure 3 that the $T_{\mathrm{i}}$ and $T_{\mathrm{s}}$ of pure PVC are $9.6 \mathrm{~min}$ and $21.8 \mathrm{~min}$, respectively, indicating that the initial color stability of pure PVC is quite short and, after having been heated for $21.8 \mathrm{~min}$, pure PVC might degrade completely. As for the PVC samples stabilized by $\mathrm{ZnSt}_{2} / \mathrm{CaSt}_{2}$, Figure $3 \mathrm{~b}$ shows that the $T_{\mathrm{i}}$ and $T_{\mathrm{s}}$ of PVC stabilized by $\mathrm{ZnSt}_{2} / \mathrm{CaSt}_{2}$ are $16.1 \mathrm{~min}$ and $24.3 \mathrm{~min}$, respectively. By comparing Figure $3 \mathrm{a}, \mathrm{b}$, although the $T_{\mathrm{i}}$ of PVC stabilized by $\mathrm{ZnSt}_{2} / \mathrm{CaSt}_{2}$ is longer than that of pure PVC, the $T_{\mathrm{s}}$ values of these two PVC samples are relatively close. This means that the initial stability of PVC stabilized with $\mathrm{ZnSt}_{2} / \mathrm{CaSt}_{2}$ was better than that of pure PVC. However, the long-term stability of PVC stabilized with $\mathrm{ZnSt}_{2} / \mathrm{CaSt}_{2}$ was worse. This is because $\mathrm{ZnCl}_{2}$ would be produced when $\mathrm{ZnSt}_{2}$ absorbed the $\mathrm{HCl}$ produced during PVC degradation. $\mathrm{ZnCl}_{2}$ was a strong Lewis acid, which would catalyze the degradation of PVC. When the amount of $\mathrm{ZnCl}_{2}$ accumulated to a certain extent, it would suddenly accelerate the degradation of PVC, leading to the rapid aging of PVC. This phenomenon is called "zinc-burning" [31]. It is worth noting that the $T_{\mathrm{i}}$ and $T_{\mathrm{S}}$ of PVC stabilized by DMAE-Zn were extended to $31.1 \mathrm{~min}$ and $67.9 \mathrm{~min}$, respectively, indicating that this PVC sample had excellent color stability and long-term stability. This might be due to the fact that DMAE-Zn has many hydroxyl groups, which might complex with the produced $\mathrm{ZnCl}_{2}$ to inhibit the catalytic degradation of PVC. 


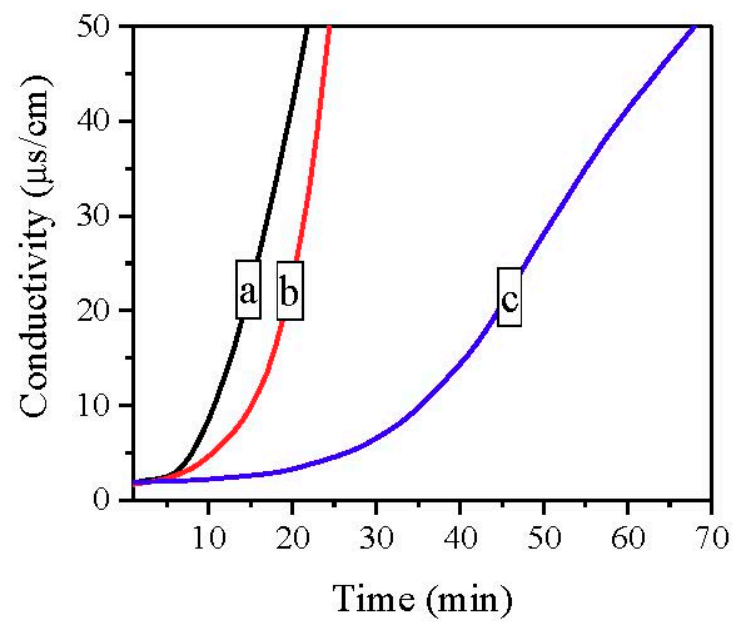

Figure 3. Conductivity versus time plots for (a) pure poly(vinyl chloride) (PVC); and PVC stabilized by 4 phr of (b) $\mathrm{CaSt}_{2} / \mathrm{ZnSt}_{2}$ (1:1); (c) DMAE-Zn.

\subsubsection{The Thermal Aging Test}

When the temperature exceeds $120^{\circ} \mathrm{C}, \mathrm{PVC}$ starts thermal degradation. The unstable chlorine atoms, such as allyl chloride and tert-butyl chloride, combine with hydrogen atoms in the ortho to form hydrogen chloride, and the $-\mathrm{C}=\mathrm{C}-$ comes into being. Further thermal degradation would produce a double bond of the conjugated structure. When the conjugated structure increases to a certain length, the color of PVC changes to light brown, then dark brown, and finally black.

Figure 4 shows the thermal aging test results of pure PVC and PVC with $4 \mathrm{phr}$ of $\mathrm{ZnSt}_{2} / \mathrm{CaSt}_{2}$ (1:3), and 1 to $4 \mathrm{phr}$ of DMAE-Zn. The initial color (heated for $0 \mathrm{~min}$ ) of pure PVC was light yellowish gray, indicating that slight thermal degradation occurred during the preparation of pure PVC sheets with the two-roll tablet press. As the heating time increased, the color of pure PVC gradually changed into light brown (after $10 \mathrm{~min}$ ), brown (after $30 \mathrm{~min}$ ), and black (after $90 \mathrm{~min}$ ). PVC samples stabilized by $\mathrm{ZnSt}_{2} / \mathrm{CaSt}_{2}$ (1:3) had an excellent initial color, showing that the formula of $\mathrm{ZnSt}_{2} / \mathrm{CaSt}_{2}$ can improve the initial color of PVC. It is worth noting from Figure 4 that, after having been heated for $40 \mathrm{~min}$, the color of PVC stabilized by $\mathrm{ZnSt}_{2} / \mathrm{CaSt}_{2}$ turned dark brown quickly, indicating the "zinc-burning" phenomenon and a poor long-term thermal stability of the formula of $\mathrm{ZnSt}_{2} / \mathrm{CaSt}_{2}$ for PVC.

\begin{tabular}{|c|c|c|c|c|c|c|c|c|c|c|c|}
\hline \multirow{2}{*}{ Stabilizers } & \multicolumn{7}{|c|}{ Degradation Time $(\times 10$ min) } \\
\cline { 2 - 11 } & 0 & 1 & 2 & 3 & 4 & 5 & 6 & 7 & 8 & 9 & 10 \\
\hline Pure PVC & & & & & & & & & & & \\
\hline 3 phr CaSt 2 1 phr ZnSt 2 & & & & & & & & & & & \\
\hline 1 phr DMAE-Zn & & & & & & & & & & & \\
\hline 2 phr DMAE-Zn & & & & & & & & & & & \\
\hline 3 phr DMAE-Zn & & & & & & & & & & & \\
\hline 4 phr DMAE-Zn & & & & & & & & & & & \\
\hline
\end{tabular}

Figure 4. Color evolution of PVC samples with different thermal stabilizers at $180^{\circ} \mathrm{C}$. 
It can be seen from Figure 4 that the initial color of PVC sheets with 1 phr of DMAE-Zn was white and changed slowly into pale yellow brown and brown within $40 \mathrm{~min}$, indicating that the addition of DMAE-Zn can improve the color stability of PVC. However, from $50 \mathrm{~min}$, the color of the PVC stabilized by $1 \mathrm{phr}$ of DMAE-Zn turned dark brown quickly within $10 \mathrm{~min}$, showing that $1 \mathrm{phr}$ of DMAE-Zn was not enough to improve the long-term thermal stability of PVC. Figure 4 proves that as the dosage of DMAE-Zn increases, the color of PVC can be improved significantly. It can also be seen from Figure 4 that the thermal stability of PVC stabilized by 2 phr and 3 phr of DMAE-Zn had a similar efficiency. PVC stabilized with $4 \mathrm{phr}$ of DMAE-Zn had the best initial color, and the color started to slowly turn yellow from $60 \mathrm{~min}$ and did not turn completely back within $120 \mathrm{~min}$. Therefore, $4 \mathrm{phr}$ of DMAE-Zn had the highest thermal stabilizing efficiency.

\subsubsection{UV-VIS Spectroscopy Test}

When the PVC is thermally degraded, a conjugated double bond structure is produced. The conjugated double bond structure has a distinct absorption peak in the UV-VIS spectrum. Furthermore, the length of the conjugated double bond affects the position of the absorption peak, and the greater the concentration of the double bond $\left(\mathrm{C}_{\mathrm{db}}\right)$, the higher the absorption peak. Figure 5 reveals the UV-VIS spectra of pure PVC and PVC stabilized by $4 \mathrm{phr}$ of different thermal stabilizers which were heated for $0 \mathrm{~min}(\mathrm{~A})$ and $60 \mathrm{~min}(\mathrm{~B})$ at $180^{\circ} \mathrm{C}$. The maximum absorption peak of three samples was at about $280 \mathrm{~nm}$, belonging to the conjugated triene structure formed in the dehydrochlorination of PVC. Pure PVC exhibited the highest $\mathrm{C}_{\mathrm{db}}$, indicating that $\mathrm{CaSt}_{2} / \mathrm{ZnSt}_{2}$ and the targeted metal alkoxides were effective in improving the initial thermal stability of PVC. Between the two thermal stabilizers, the peak height of PVC stabilized with $\mathrm{CaSt}_{2} / \mathrm{ZnSt}_{2}$ was the higher one, suggesting that the formula with a ratio of $\mathrm{CaSt}_{2}$ to $\mathrm{ZnSt}_{2}$ of 3 was not effective in improving the initial color of PVC, probably because there was less $\mathrm{ZnSt}_{2}$ and more $\mathrm{CaSt}_{2}\left(\mathrm{ZnSt}_{2}\right.$ is the best additive in improving the initial color of PVC). As for the targeted DMAE-Zn, Figure 5A shows that the peak height of PVC stabilized by DMAE-Zn was the lowest, indicating the lowest $C_{d b}$ in PVC stabilized by DMAE-Zn. These results confirmed that DMAE-Zn is the most efficient in preventing PVC molecules from forming conjugated structures, and thus preventing the thermal degradation of PVC, consistent with the results of the oven thermal aging tests.

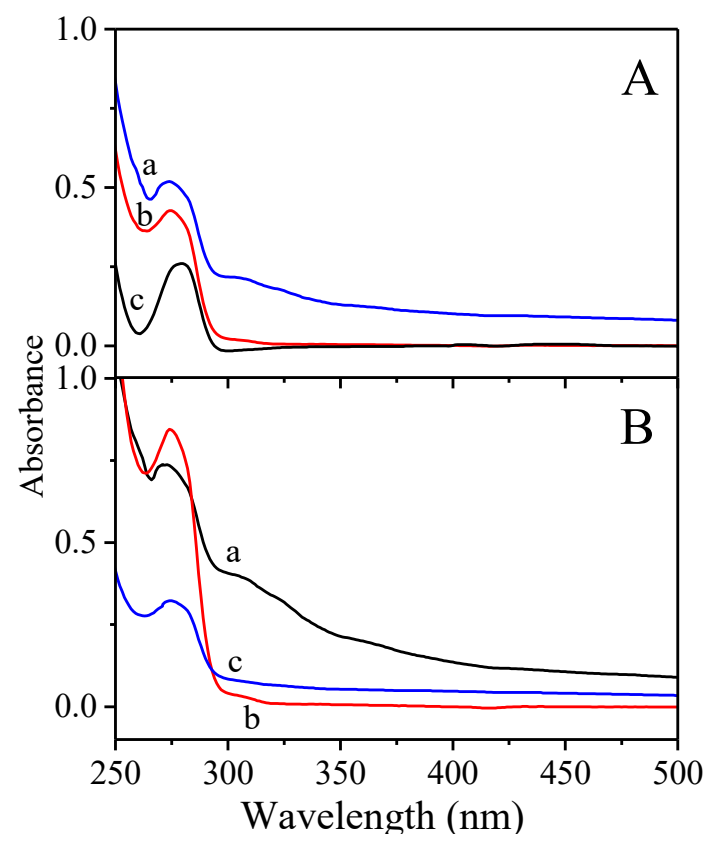

Figure 5. UV-VIS spectrum of pure PVC and PVC stabilized with different thermal stabilities heated for $0 \mathrm{~min}(\mathbf{A})$ and $60 \mathrm{~min}(\mathbf{B})$ at $180^{\circ} \mathrm{C}$. a: Pure PVC; b: CaSt $2 / \mathrm{ZnSt}_{2} ; \mathrm{c}$ : DMAE-Zn. 
Compared with Figure $5 \mathrm{~A}$, the $\mathrm{C}_{\mathrm{db}}$ of PVC samples in Figure $5 \mathrm{~B}$ increased greatly. In particular, after having been heated for $60 \mathrm{~min}$, the $\mathrm{C}_{\mathrm{db}}$ of PVC stabilized with $\mathrm{CaSt}_{2} / \mathrm{ZnSt}_{2}$ having the largest value, even exceeding that of pure PVC. This is because the "zinc-burning" phenomenon occurred in PVC stabilized by $\mathrm{CaSt}_{2} / \mathrm{ZnSt}_{2}$. The results of the oven thermal aging tests (Figure 4) also confirmed this conclusion, as the color of the PVC sheet stabilized by CaSt $2 / \mathrm{ZnSt}_{2}$ became dark gray after being heated for only $60 \mathrm{~min}$. The $\mathrm{C}_{\mathrm{db}}$ of PVC stabilized by the synthesized DMAE-Zn did not increase significantly, but only increased from 0.26 to 0.32 , indicating that DMAE-Zn had the highest efficiency in suppressing the production of conjugated double bonds.

The position of absorption peaks should also be noted. Comparing Figure 5A,B, it can be seen that the position of these main absorption peaks did not shift, showing that most of the PVC thermal degradation products have a conjugated triene structure. However, the absorbance curve of pure PVC (see curve a in Figure 5A) showed that there was weak absorption at the range of 300-330 nm which belongs to tetraenes and pentaene. PVC samples stabilized by the two thermal stabilizers had no absorption at the same range. Figure $5 \mathrm{~B}$ shows that, after having been heated for $60 \mathrm{~min}$, the absorbance curve of pure PVC increased obviously in the range of $300-330 \mathrm{~nm}$. This suggests that the $C_{\mathrm{db}}$ of tetraenes and pentaene in pure PVC had further increased. The absorbance curve of PVC stabilized by DMAE-Zn increased slightly in the range of 300-330 $\mathrm{nm}$. Surprisingly, the absorbance curve of PVC stabilized by CaSt $2 / \mathrm{ZnSt}_{2}$ still did not increase, indicating that the $\mathrm{ZnCl}_{2}$ produced from the reaction between $\mathrm{ZnSt}_{2}$ and $\mathrm{HCl}$ intended to catalyze the PVC degradation only formed a conjugated triene structure.

\subsubsection{Synergy between DMAE-Zn and $\mathrm{CaSt}_{2}$ or $\mathrm{ZnSt}_{2}$ on PVC Thermal Stability}

The above results (Sections 3.2.1-3.2.3) indicate that DMAE-Zn is an efficient thermal stabilizer for PVC. In order to improve PVC color thermal stability and reduce manufacturing costs (if this method can be industrialized), the synergistic effect of DMAE-Zn with CaSt $t_{2}$ and $\mathrm{ZnSt}_{2}$ on PVC thermal stability was investigated. Figure 6 shows the oven thermal aging test results of PVC stabilized by $\mathrm{CaSt}_{2} / \mathrm{DMAE}-\mathrm{Zn}$ and that stabilized by $\mathrm{ZnSt}_{2} / \mathrm{DMAE}-\mathrm{Zn}$. It can be seen from the figure that the color of PVC stabilized by $4 \mathrm{phr}$ of $\mathrm{CaSt}_{2}$ started to turn light brown after being heated for $10 \mathrm{~min}$, and turned darker brown at $60 \mathrm{~min}$, showing that pure $\mathrm{CaSt}_{2}$ cannot improve the PVC thermal stability significantly. The color of PVC with $3 \mathrm{phr}$ of $\mathrm{CaSt}_{2}+1 \mathrm{phr}$ of DMAE-Zn turned black at 60 min, indicating that the thermal stability of this formula is similar to that of pure $\mathrm{CaSt}_{2}$. With increasing DMAE-Zn, the thermal stability of PVC was improved quickly. For example, the color of PVC stabilized by $\mathrm{CaSt}_{2} / \mathrm{DMAE}-\mathrm{Zn}$ with mass ratios of 2:2 and 1:3 did not turn black until $120 \mathrm{~min}$. Moreover, the color of PVC stabilized by $\mathrm{CaSt}_{2} / \mathrm{DMAE}-\mathrm{Zn}$ with a mass ration of 1:3 did not change within $30 \mathrm{~min}$, and only turned slightly brown within the next $40 \mathrm{~min}$, indicating that there existed a good synergistic effect between $\mathrm{CaSt}_{2}$ and DMAE-Zn on PVC thermal stability.

As for the system of $\mathrm{ZnSt}_{2} / \mathrm{DMAE}-\mathrm{Zn}$, Figure 6 shows that, when $\mathrm{ZnSt}_{2}$ was used alone as a PVC thermal stabilizer, PVC samples turned black quickly within 10 min due to the "zinc-burning" phenomenon. With the dosage of DMAE-Zn increasing, the initial color and long-term stability of PVC can be improved obviously. For example, the color of PVC stabilized by $\mathrm{ZnSt}_{2} / \mathrm{DMAE}^{\mathrm{Zn}}$ with a mass ratio of 1:3 remained unchanged in $70 \mathrm{~min}$, and did not turn black in $120 \mathrm{~min}$. Therefore, there existed an excellent synergistic effect between $\mathrm{ZnSt}_{2}$ and DMAE-Zn on PVC thermal stability. This was probably due to the large number of hydroxyl groups in DMAE-Zn, which could complex with $\mathrm{ZnCl}_{2}$ to avoid catalyzing PVC thermal degradation. 


\begin{tabular}{|c|c|c|c|c|c|c|c|c|c|c|c|c|c|c|}
\hline \multicolumn{2}{|c|}{ Stabilizers } & \multicolumn{13}{|c|}{ Degradation Time $(\times 10 \mathrm{~min})$} \\
\hline Formulation & Mass & 0 & 1 & 2 & 3 & 4 & 5 & 6 & 7 & 8 & 9 & 10 & 11 & 12 \\
\hline \multirow{4}{*}{$\mathrm{CaSt} / \mathrm{DMAE}-\mathrm{Zn}$} & $4 / 0$ & & & & & & & & & & & & & \\
\hline & $3 / 1$ & & & & & & & & & & & & & \\
\hline & $2 / 2$ & & & & & & & & & & & & & \\
\hline & $1 / 3$ & & & & & & & & & & & & & \\
\hline \multirow{4}{*}{$\mathrm{ZnSt} / \mathrm{DMAE}-\mathrm{Zn}$} & $4 / 0$ & & 6 & & & & & & & & & & & \\
\hline & $3 / 1$ & & & & & & & & & & & & & \\
\hline & $2 / 2$ & & & & & & & & & & & & & \\
\hline & $1 / 3$ & & & & & & & & & & & & & \\
\hline
\end{tabular}

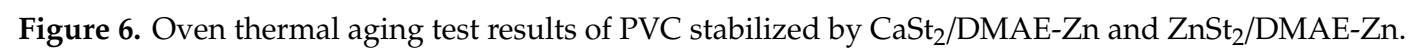

\subsubsection{Torque Rheology Test of DMAE-Zn}

The torque rheology test was conducted according to ASTM D 2538-02 [32], and operated at $180^{\circ} \mathrm{C}$ as was described in Section 2.5.4. Figure 7 shows the results for pure PVC and PVC stabilized by DMAE-Zn. Both samples had two distinct peaks which were the feed peak and the plasticized peak of PVC resin. The first peaks for both samples appeared at almost the same time. The first peak height of PVC stabilized by DMAE-Zn was $50 \mathrm{Nm}$ higher than that of pure PVC, indicating that the addition of DMAE-Zn did not improve the lubricating property of PVC. The second peaks of pure PVC and PVC stabilized by DMAE-Zn appeared at different time points. Pure PVC required approximately $111 \mathrm{~s}$ to complete the plasticization. In PVC stabilized by DMAE-Zn case, however, plasticization was completed in $55 \mathrm{~s}$. The significantly reduced plasticizing time obtained by incorporating DMAE-Zn as compared to pure PVC confirmed the excellent plasticizing effect of DMAE-Zn on PVC. It is well known that plasticizers must have a good compatibility with PVC. For example, Gilbert et al. reported that plasticizers acted as solvents for amorphous regions of PVC, and the PVC chains in the amorphous regions might become solvated at elevated temperatures during processing [33]. Therefore, we concluded that DMAE-Zn had a good plasticizing effect on PVC because DMAE-Zn has a good compatibility with PVC chains in the amorphous regions. It is also worth noting that the balance torque of PVC stabilized by DMAE-Zn was slightly lower than that of pure PVC. Considering that DMAE-Zn had no lubricity to PVC, the lower balance torque of PVC stabilized by DMAE-Zn indicated that the addition of DMAE-Zn could decrease friction between PVC molecules through solvation. 


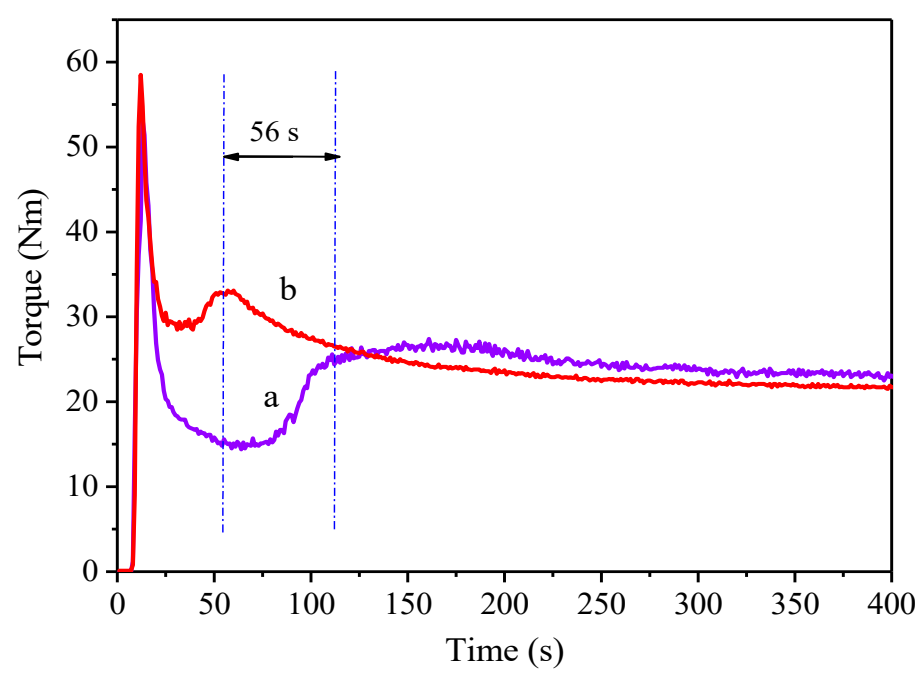

Figure 7. Torque rheology test results obtained at $180{ }^{\circ} \mathrm{C}$ on pure PVC (a) and PVC stabilized by DMAE-Zn (b).

\subsection{The Thermal Stabilizing Mechanism of DMAE-Zn}

In our previous work we found that, due to its high electronegativity, the alkyl oxygen of metal alkoxides had a tendency to attack the carbon atoms (given its high positive charge) attached to allyl chloride in PVC chains [34]. At the same time, allyl chloride with a high electronegativity would attack the zinc atom (having a high positive charge) of the metal alkoxides. Scheme 2 illustrates the reaction mechanism. This reaction mechanism also applies to DMAE-Zn since it contains metal alkoxides, which could explain the fact that PVC stabilized by DMAE-Zn had a better initial color (i.e., white) than pure PVC (refer to Figure 4). The allyl chloride in PVC formed a bond with the Zn atom in DMAE-Zn. The released $\mathrm{Cl}$ atoms from PVC were taken up by zinc ions in DMAE-Zn (Scheme 2a) to generate compound I, which prevented the formation of free $\mathrm{ZnCl}_{2}$. This explains the excellent long-term thermal stability observed for PVC stabilized by DMAE-Zn (Figure 4).

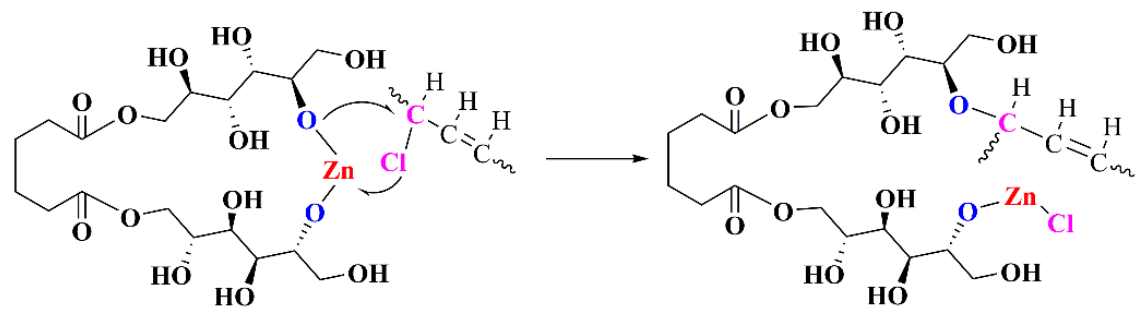

(a)

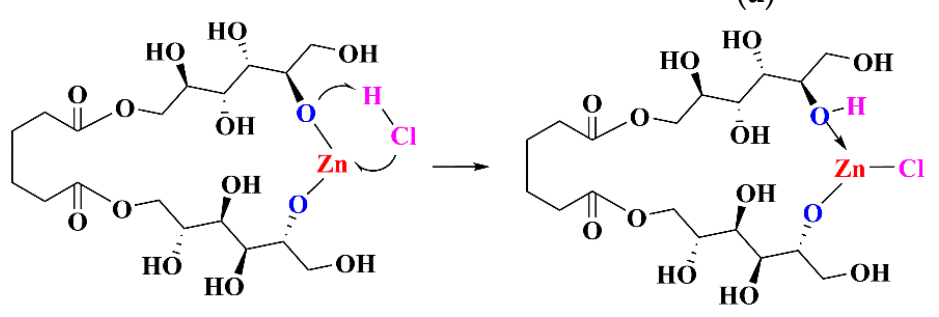

(b)
Compound I

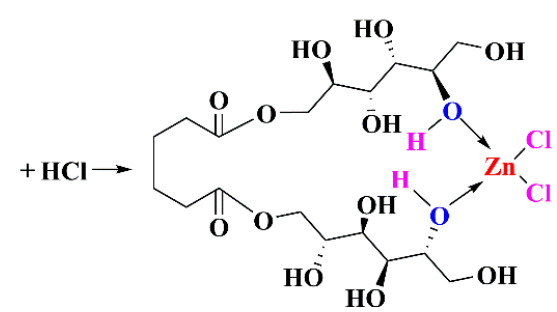

Compound II

Scheme 2. Cont. 


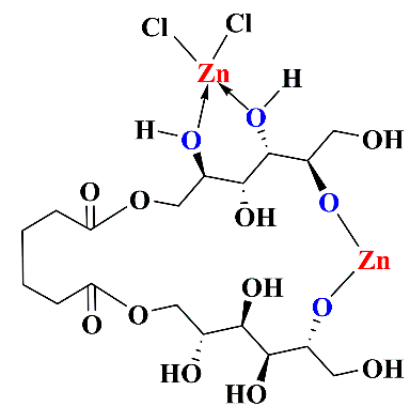

Compound III

(c)

Scheme 2. The schematic diagram of DMAE-Zn to replace allyl chloride (a), to neutralize $\mathrm{HCl}(\mathbf{b})$, and to complex $\mathrm{ZnCl}_{2}$ (c).

In order to verify this mechanism of DMAE-Zn, FT-IR spectra were used to test pure PVC sheets and PVC sheets stabilized by DMAE-Zn and heated at $180^{\circ} \mathrm{C}$ for $0 \mathrm{~min}$ and $30 \mathrm{~min}$. Figure 8 shows the FT-IR results. The obvious absorption peaks at $1096 \mathrm{~cm}^{-1}$ in curves $\mathrm{c}$ and $\mathrm{d}$ are the characteristic peaks corresponding to $-\mathrm{C}-\mathrm{O}-\mathrm{C}-$. The existence of $-\mathrm{C}-\mathrm{O}-\mathrm{C}-$ improved the feasibility of the mechanism of DMAE-Zn to replace allyl chloride in PVC molecules-the alkyl oxygen of metal alkoxides attacked the carbon atom attached to allyl chloride in the PVC molecule and the allyl chloride atom attacked the zinc atom in DMAE-Zn (as shown in Scheme 2a), and then formed compound I. As a comparison, there was no characteristic absorption peak at $1096 \mathrm{~cm}^{-1}$ in curves a and $\mathrm{b}$.

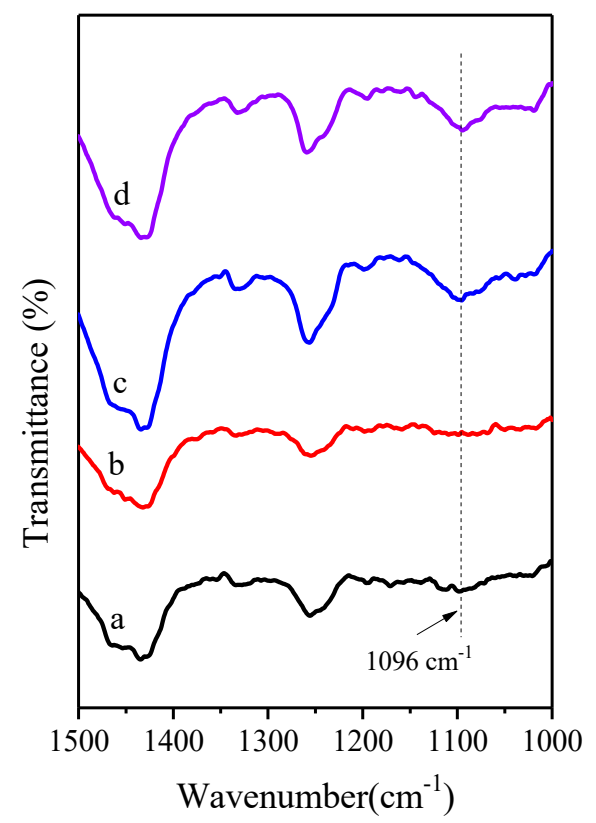

Figure 8. FT-IR spectra of pure PVC and PVC stabilized by DMAE-Zn and heated at $180{ }^{\circ} \mathrm{C}$. Initial pure PVC sheet (a); pure PVC sheet heated for $30 \mathrm{~min}$ (b); initial PVC sheet stabilized by DMAE-Zn (c); PVC sheet stabilized by DMAE-Zn heated for $30 \mathrm{~min}(\mathbf{d})$.

A conductivity titration experiment was carried out to verify the ability of DMAE-Zn to absorb $\mathrm{HCl}$. The experimental method is described in Section 2.5.5. The results are shown in Table 1. Table 1 shows that lead salts had the highest capacity to absorb $\mathrm{HCl}$, reaching $281.1 \mathrm{mg} / \mathrm{g}$. The $\mathrm{HCl}$ absorption capacity of DMAE-Zn was $131.4 \mathrm{mg} / \mathrm{g}$, which was larger than that of $\mathrm{ZnSt}_{2}$ and $\mathrm{CaSt}_{2}$, showing that DMAE-Zn could improve the long-term thermal stability of PVC. 
Table 1. The $\mathrm{HCl}$ absorption capacity of different thermal stabilizers for PVC.

\begin{tabular}{cc}
\hline Stabilizer & HCl Absorption Capacity, $\mathbf{~ m g ~ ( H C l ) / g ~ ( S t a b i l i z e r ) ~}$ \\
\hline Lead salts & 280.1 \\
$\mathrm{ZnSt}_{2}$ & 98.2 \\
$\mathrm{CaSt}_{2}$ & 87.6 \\
DMAE-Zn & 131.4 \\
\hline
\end{tabular}

In general, the addition of an auxiliary thermal stability is very important if a zinc atom is present in the thermal stability due to the "zinc-burning" phenomenon. It can be seen in Figure 4 that there was no "zinc-burning" phenomenon on PVC samples stabilized with pure DMAE-Zn. Furthermore, the PVC sample stabilized by $3 \mathrm{phr}$ of DMAE- $\mathrm{Zn}+1 \mathrm{phr}$ of $\mathrm{ZnSt}_{2}$ also had good long-term thermal stability. All the results indicate that the $\mathrm{ZnCl}_{2}$ produced during the replacement of the active chlorine atom or the neutralization of $\mathrm{HCl}$ can be chelated by -OH of DMAE-Zn in situ (illustrated in Scheme $2 \mathrm{~b}, \mathrm{c}$ ) and generate compounds II and III. In order to verify the complexation of DMAE- $\mathrm{Zn}$ with $\mathrm{ZnCl}_{2}$, oven thermal aging experiments were conducted to test the thermal stability of PVC samples stabilized by $4 \mathrm{phr}$ of pure $\mathrm{ZnCl}_{2}$, and $4 \mathrm{phr}$ of different proportions of $\mathrm{ZnCl}_{2} / \mathrm{DMAE-Zn}$ mixtures. The results are shown in Figure 9. PVC samples containing $4 \mathrm{phr} \mathrm{ZnCl}_{2}$ quickly darkened in $10 \mathrm{~min}$. This demonstrated that $\mathrm{ZnCl}_{2}$ accelerated the thermal degradation of PVC, meaning that the "zinc-burning" phenomenon occurred. With the increase of the ratio of DMAE-Zn, the initial color and long-term stability of PVC stabilized by $\mathrm{ZnCl}_{2} / \mathrm{DMAE}-\mathrm{Zn}$ mixture can be improved. In particular, the PVC samples with $1 \mathrm{phr}$ of $\mathrm{ZnCl}_{2}+3 \mathrm{phr}$ of DMAE-Zn exhibited excellent thermal stability, as shown in Figure 9, since the initial color did not change within $50 \mathrm{~min}$ and became black completely after being heated for $70 \mathrm{~min}$. In the end, the PVC samples with 1 phr of $\mathrm{ZnCl}_{2}+3$ phr of DMAE-Zn also showed the "zinc-burning" phenomenon, because it exceeded the ability of DMAE- $\mathrm{Zn}$ to chelate $\mathrm{ZnCl}_{2}$.

\begin{tabular}{|c|c|c|c|c|c|c|c|c|c|}
\hline Stabilizers & \multicolumn{7}{|c|}{ Degradation Time $(\times 10$ min) } \\
\hline $\begin{array}{c}\mathrm{ZnCl}_{2} \text { DMAE- } \\
\mathrm{Zn}\end{array}$ & 0 & 1 & 2 & 3 & 4 & 5 & 6 & 7 & 8 \\
\hline $4 / 0$ & & & & & & & & & \\
\hline $3 / 1$ & & & & & & & & & \\
\hline $2 / 2$ & & & & & & & & & \\
\hline $1 / 3$ & & & & & & & & & \\
\hline
\end{tabular}

Figure 9. Color evolution of PVC samples with different ratios of $\mathrm{ZnCl}_{2}$ and DMAE-Zn heated at 180 ${ }^{\circ} \mathrm{C}$ for different periods of time.

\section{Conclusions}

In this study, DMAE-Zn was synthesized through an alcoholysis reaction. The chemical formations were confirmed through FT-IR. The thermal stability of PVC was studied using thermal aging tests, conductivity tests, UV-VIS spectroscopy tests, and torque rheology tests. The results showed that PVC stabilized by DMAE-Zn had a good initial color and long-term stability, as well as good plasticizing performance. Moreover, the results of the oven thermal aging experiments indicated that there was good synergy among DMAE-Zn, CaSt ${ }_{2}$, and $\mathrm{ZnSt}_{2}$ in improving the durability of PVC under 
long-term exposure to heat. Furthermore, the thermal stabilizing mechanism of DMAE-Zn on PVC was studied through FT-IR, $\mathrm{HCl}$ absorption capacity tests, and compound experiments with $\mathrm{ZnSt}_{2}$. The results confirmed that DMAE-Zn has the common characteristic of metal alkoxides, which can readily neutralize $\mathrm{HCl}$. FT-IR showed that it was the alkoxy group of DMAE-Zn that replaced the unstable chlorine atoms on PVC chains to improve the initial color and thermal stability of PVC. The $\mathrm{HCl}$ absorption capacity of DMAE-Zn $\left(131.4 \mathrm{mg} / \mathrm{g}\right.$ ) was larger than that of $\mathrm{ZnSt}_{2}$ and $\mathrm{CaSt}_{2}$, indicating that DMAE-Zn can improve the long-term thermal stability of PVC. It was also found that there were plenty of hydroxy groups on DMAE-Zn which could complex $\mathrm{ZnCl}_{2}$ to delay or avoid the "zinc-burning" phenomenon.

Author Contributions: Formal analysis, B.A.; Funding acquisition, L.Z.; Investigation, Y.L., D.L., W.H., M.Z., and Z.C.; Project administration, D.L.; Resources, D.L.; Writing—original draft, Y.L.; Writing—review and editing, D.L., L.Z., and H.S.

Funding: The authors gratefully acknowledge the support of the University Research Program of Shandong Provincial Department of Education (No. J16LC24), the SDUT and Zibo City Integration Development Project (No. 2016ZBXC057), the National Natural Science Foundation of China (No. 21506118), the Key Research and Development Program of Shandong Province (2017GGX40102), and the Yellow River Delta Research Institute Innovation Research Fund Project.

Conflicts of Interest: The authors declare no conflict of interest.

\section{References}

1. Avalos, A.S.; Hakkarainen, M.; Odelius, K. Superiorly plasticized PVC/PBSA blends through crotonic and acrylic acid functionalization of PVC. Polymers 2017, 9, 84. [CrossRef] [PubMed]

2. Fu, M.; Li, D.; Liu, H.; Zhang, J. Insights into the use of zinc-mannitol alkoxide as a novel thermal stabilizer for rigid poly(vinyl chloride). J. Appl. Polym. Sci. 2015, 132, 42038. [CrossRef]

3. Wang, M.; Xu, J.; Wu, H.; Guo, S. Effect of pentaerythritol and organic tin with calcium/zinc stearates on the stabilization of poly(vinyl chloride). Polym. Degrad. Stab. 2006, 91, 2101-2109. [CrossRef]

4. Chen, J.; Liu, Z.; Wang, K.; Huang, J.; Li, K.; Nie, X.; Jiang, J. Epoxidized castor oil-based diglycidyl-phthalate plasticizer: Synthesis and thermal stabilizing effects on poly(vinyl chloride). J. Appl. Polym. Sci. 2018, 135, 47142. [CrossRef]

5. Castañeda-Facio, A.; Benavides, R.; Martínez-Pardo, M.E. Thermal stability of PVC formulations gamma irradiated at different dose rates. Radiat. Phys. Chem. 2014, 97, 75-80. [CrossRef]

6. Lu, W.; Yang, Q.; Yan, B.; Cheng, Y. Plasma-assisted synthesis of chlorinated polyvinyl chloride (CPVC) characterized by online UV-Vis analysis. Chem. Eng. 2012, 207-208, 923-930. [CrossRef]

7. Meng, H.; Wang, S.; Chen, L.; Wu, Z.; Zhao, J. Investigation on Synergistic Effects and Char Morphology during Copyrolysis of Poly(vinyl chloride) Blended with Different Rank Coals from Northern China. Energy Fuels 2015, 29, 6645-6655.

8. Xu, R.; Song, L.; Teng, Y.; Xia, J. Ferrous chloride-induced modification on thermal properties of polyvinyl chloride. Thermochim. Acta 2013, 565, 205-210. [CrossRef]

9. Jeen, M.; Balanand, S.; Peer, M.; Ananthakumar, S. Design and fabrication of flexible polyvinyl chloride dielectric composite reinforced with ZnO microvaristors. J. Appl. Polym. Sci. 2017, 135, 46031.

10. Li, M.; Zhang, J.; Xin, J.; Huang, K.; Li, S.; Wang, M.; Xia, J. Design of green zinc-based thermal stabilizers derived from tung oil fatty acid and study of thermal stabilization for PVC. J. Appl. Polym. Sci. 2016, 133, 44679. [CrossRef]

11. Ye, F.; Ye, Q.F.; Zhan, H.H.; Ge, Y.Q.; Ma, X.T.; Xu, Y.Y.; Wang, X. Synthesis and Study of Zinc Orotate and Its Synergistic Effect with Commercial Stabilizers for Stabilizing Poly(Vinyl Chloride). Polymers 2019, 11, 194. [CrossRef]

12. Reddeppa, N.; Ramamohan, K.; Ravi, M.; Guo, X. Effects of potassium iodide (KI) on crystallinity, thermal stability, and electrical properties of polymer blend electrolytes (PVC/PEO:KI). Solid State Ionics 2015, 278, 260-267.

13. Ritu, S.; Deepak, P. Polyvinyl chloride degradation by Hybrid (Chemical and biological) Modification. Polym. Degrad. Stab. 2016, 123, 80-94. 
14. Emad, Y.; Jumat, S.; Nadia, S. New photostabilizers for PVC based on some diorganotin(IV) complexes. J. Saudi Chem. Soc. 2015, 19, 133-141.

15. Fiaz, S.M.; Mark, C.; Amber, C.R.; Steven, R.S.; Jackson, S.; Esteban, U.; Rani, J.; Jeffrey, M.C.; Bharat, I.C.; Pamela, P.; et al. Enhanced thermal stabilization and reduced color formation of plasticized Poly(vinyl chloride) using zinc and calcium salts of 11-maleimideoundecanoic acid. Polym. Degrad. Stab. 2015, 111, 64-70.

16. Wang, M.; Xia, J.; Jiang, J.; Li, S.; Huang, K.; Mao, W.; Li, M. A novel liquid Ca/Zn thermal stabilizer synthesized from tung-maleic anhydride and its effects on thermal stability and mechanical properties of PVC. Polym. Degrad. Stab. 2016, 133, 136-143. [CrossRef]

17. Zhang, Z.; Wang, S.; Zhang, J.; Zhu, W.; Tian, T. Remarkably improved toughness and thermal stability of poly (vinyl chloride) (PVC)/poly (a-methylstyrene-acrylonitrile) (a-MSAN) blend with the assistance of two impact modifiers. Polym. Test. 2016, 51, 1-5. [CrossRef]

18. Zhu, L.; Wu, Y.; Shentu, B.; Weng, Z. Preparation and characterization of zinc-mannitol complexes as PVC thermal stabilizers with high efficiency. Polym. Degrad. Stab. 2016, 133, 399-403. [CrossRef]

19. Wang, M.; Jiang, J.C.; Xia, J.L.; Li, S.H.; Li, M. Phosphate ester groups-containing ricinoleic acid-based $\mathrm{Ca} / \mathrm{Zn}$ : Preparation and application as novel thermal stabilizer for PVC. J. Appl. Polym. Sci. 2018, 135, 45940. [CrossRef]

20. Benavides, R.; Edge, M.; Allen, N.; Téllez, M. Stabilization of Poly(vinyl chloride) with Preheated Metal Stearates and Costabilizers. I. Use of a $\beta$-Diketone. J. Appl. Polym. Sci. 1998, 68, 1-10. [CrossRef]

21. Johan, S.; Rik, L.; Daan, S.V.; Jacco, V.; John, W.G.; Leonardus, W.J. Long-term heat stabilisation by (natural) polyols in heavy metal- and zinc-free poly(vinyl chloride). Polym. Degrad. Stab. 2006, 91, 52-59.

22. Daan, S.V.; Johan, S.; Guus, E.F.; Hans, C.V.; Jacco, V.; John, W.G.; Leonardus, W.J. The compatibility of (natural) polyols with heavy metal- and zinc-free poly(vinyl chloride): Their effect on rheology and implications for plate-out. Polym. Degrad. Stab. 2008, 93, 50-58.

23. Xie, L.; Li, D.; Fu, M.; Zhang, J.; Zhang, L.; Zhang, Y.; Zhao, P. Study on Lanthanum-Pentaerythritol Alkoxide as a Thermal Stabilizer for Rigid Polyvinyl Chloride. J. Vinyl Addit. Technol. 2017, 23, 55-61. [CrossRef]

24. Xu, S.; Li, D.; Yu, X.; Zhang, Y.; Yu, Y.; Zhou, M.; Tang, S. Study on Pentaerythritol-Zinc as a Novel Thermal Stabilizer for Rigid Poly(Vinyl Chloride). J. Appl. Polym. Sci. 2012, 126, 569-574. [CrossRef]

25. Li, D.; Xie, L.; Fu, M.; Zhang, J.; Indrawirawan, S.; Zhang, Y.; Tang, S. Synergistic effects of lanthanumpentaerythritol alkoxide with zinc stearates and with $\beta$-diketone on the thermal stability of poly(vinyl chloride). Polym. Degrad. Stab. 2015, 114, 52-59. [CrossRef]

26. Liu, H.; Li, D.; Li, R.; Sun, H.; Zhang, Y.; Zhang, L.; Zhao, P. Synthesis of Pentaerythritol Stearate Ester-Based Zinc Alkoxide and Its Synergistic Effect with Calcium Stearate and Zinc Stearate on PVC Thermal Stability. J. Vinyl Addit. Technol. 2017, 24, 314-323. [CrossRef]

27. Dong, T.; Li, D.; Li, Y.; Han, W.; Li, Z.; Xie, G.; Sunarsob, J.; Liu, S. Design and synthesis of polyol ester-based zinc metal alkoxides as a bi-functional thermal stabilizer for poly(vinyl chloride). Polym. Degrad. Stab. 2019, 159, 125-132. [CrossRef]

28. Xie, L.; Li, D.; Zhang, J. The Effect of Pentaerythritol-Aluminum on the Thermal Stability of Rigid Poly(vinyl chloride). J. Appl. Polym. Sci. 2013, 130, 3704-3709. [CrossRef]

29. Benaniba, M.T.; Massardier-Nageotte, V. Evaluation effects of biobased plasticizer on the thermal, mechanical, dynamical mechanical properties, and permanence of plasticized PVC. J. Appl. Polym. Sci. 2010, 118, 3499-3508. [CrossRef]

30. Erdoğdu, C.A.; Atakul, S.; Balköse, D.; Ülkü, S. Development of Synergistic Heat Stabilizers for PVC from Zinc Borate-Zinc Phosphate. Chem. Eng. Commun. 2008, 196, 148-160. [CrossRef]

31. Fu, M.; Li, D.; Liu, H.; Ai, H.; Zhang, Y.; Zhang, L. Synergistic effects of zinc-mannitol alkoxide with calcium/zinc stearates and with $\beta$-diketone on thermal stability of rigid poly(vinyl chloride). J. Polym. Res. 2016, 23, 13-23. [CrossRef]

32. Standard Practice for Fusion of Poly(vinyl chloride) (PVC) Compounds Using a Torque Rheometer; ASTM D2538-02(2010); ASTM International: West Conshohocken, PA, USA, 2010. 
33. Van Oosterhout, J.T.; Gilbert, M. Interactions between PVC and binary or ternary blends of plasticizers. Part I. PVC/plasticizer compatibility. Polymer 2003, 44, 8081-8094. [CrossRef]

34. Li, D.; Zhou, M.; Xie, L.; Yu, X.; Yu, Y.; Ai, H.; Tang, S. Synergism of pentaerythritol-zinc with b-diketone and calcium stearate in poly(vinyl chloride) thermal stability. Polym. J. 2013, 45, 775-782. [CrossRef]

(C) 2019 by the authors. Licensee MDPI, Basel, Switzerland. This article is an open access article distributed under the terms and conditions of the Creative Commons Attribution (CC BY) license (http://creativecommons.org/licenses/by/4.0/). 